\title{
Notes on the vocalizations of New Caledonian Myzomela (Myzomela caledonica) and Scarlet Myzomela (Myzomela sanguinolenta)
}

\section{Peter Boesman}

In the following we briefly analyze and compare voice of New Caledonian Myzomela (Myzomela caledonica) and Scarlet Myzomela (Myzomela sanguinolenta). We also try to quantify the extent of any vocal differences using the criteria proposed by Tobias et al. (2010), as a support for taxonomic review. We have made use of sound recordings available on-line from Xeno Canto (XC) and Macaulay Library (ML).

There are only a few recordings available of $M$. caledonica:

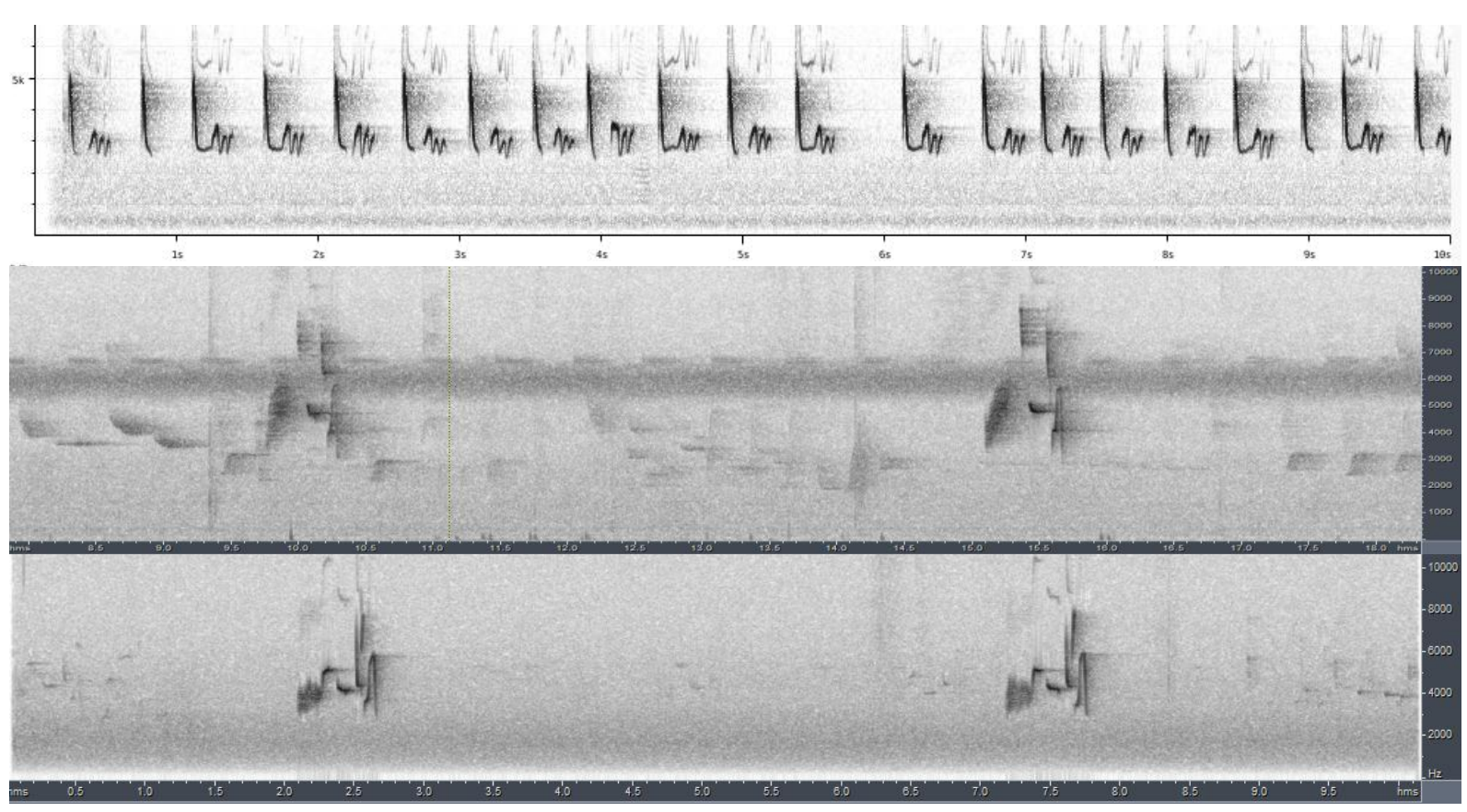

to be compared with M. sanguinolenta:

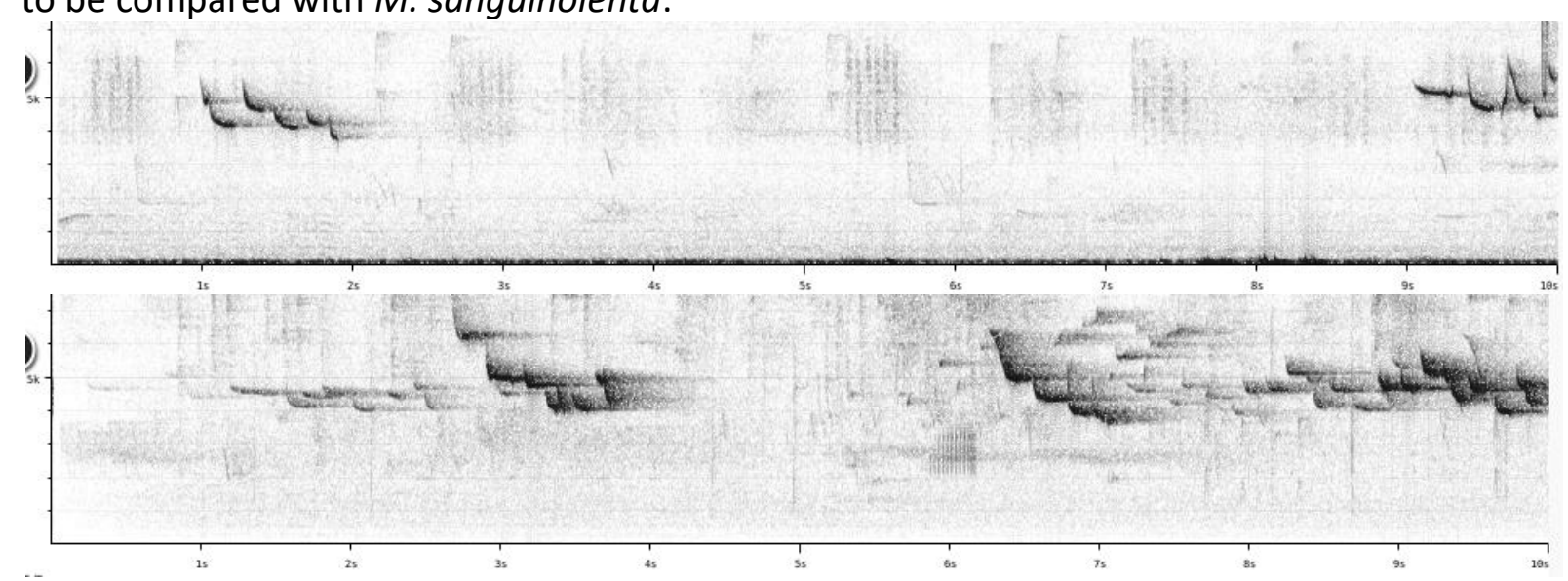



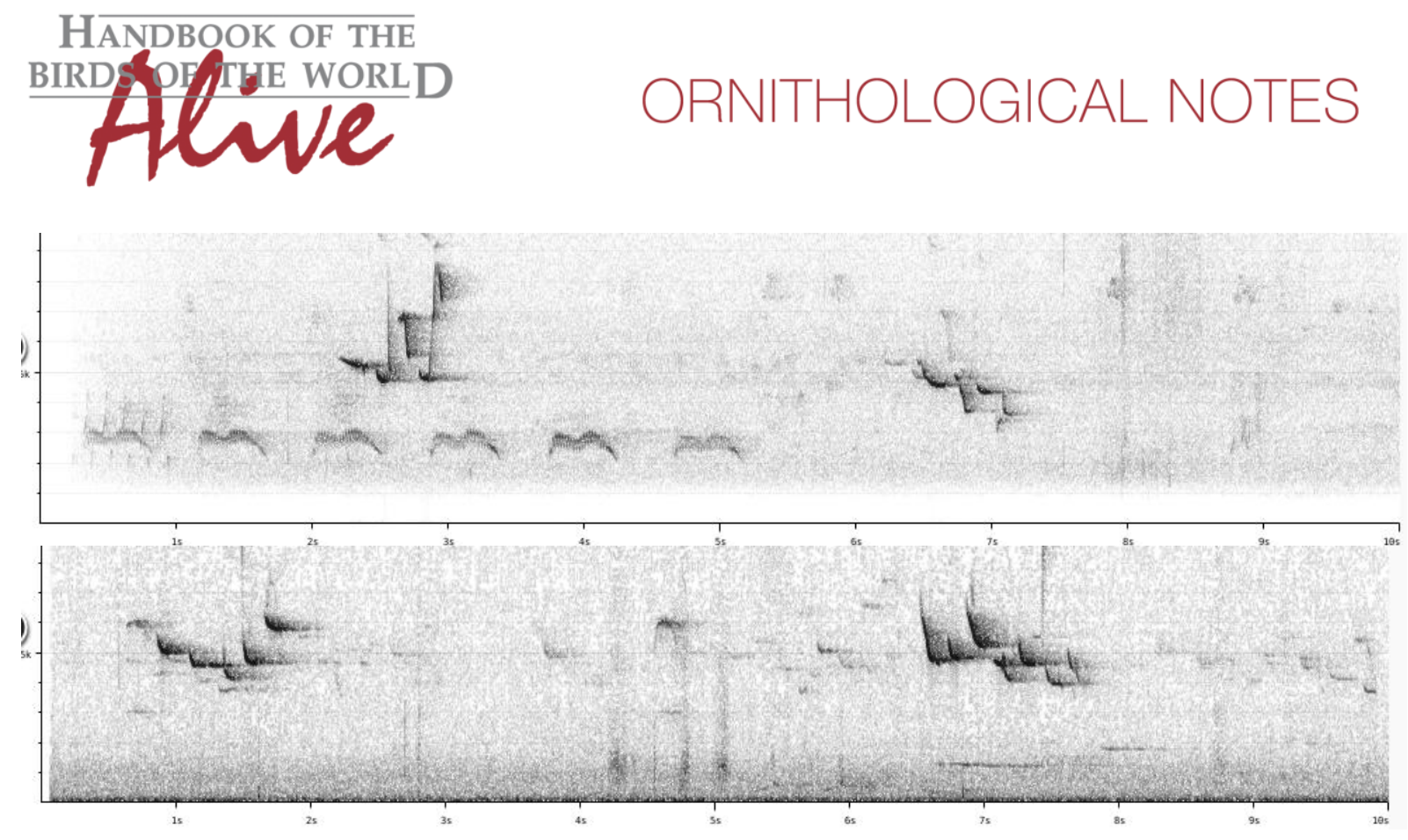

Despite the limited number of recordings for caledonica which possibly don't illustrate the full extent of vocal variation, voice of both taxa seems to be quite different:

* minimum frequency in caledonica is c $2800-3000 \mathrm{~Hz}$ vs $3500-4000 \mathrm{~Hz}$ in sanguinolenta, the latter thus clearly higher pitched (score 2-3).

* caledonica typically has at least one burry or trilled note vs much more tinkling notes in sanguinolenta

* sanguinolenta seems to have 2 typical song phrases, either a sweet phrase gradually descending in pitch and often again ascending towards the end, or a short higher-pitched tinkling phrase, both quite different from the more emphatic vocalisations of caledonica (score 1-2).

Vocal differences thus seem to be quite significant. More recordings of caledonica are needed however to obtain a better understanding of its full vocabulary.

This note was finalized on 20th June 2016, using sound recordings available on-line at that moment. We would like to thank the many sound recordists who placed their recordings for these species on XC and ML, in particular Patrik Åberg and Lucas DeCicco for recordings of caledonica.

\section{References}

Tobias, J.A., Seddon, N., Spottiswoode, C.N., Pilgrim, J.D., Fishpool, L.D.C. \& Collar, N.J. (2010). Quantitative criteria for species delimitation. Ibis 152(4): 724-746.

\section{Recommended citation}

Boesman, P. (2016). Notes on the vocalizations of New Caledonian Myzomela (Myzomela caledonica) and Scarlet Myzomela (Myzomela sanguinolenta). HBW Alive Ornithological Note 417. In: Handbook of the Birds of the World Alive. Lynx Edicions, Barcelona. (retrieved from 
HANDBOOK OF THE

BIRDS PI THE WORLD

ORNITHOLOGICAL NOTES

http://www.hbw.com/node/1253821 on 6 December 2016).

3 